J. Lake Sci. (湖泊科学) , 2011, 23(2): 295-302

http: //www. jlakes. org. E-mail : jlakes@niglas.ac.cn

(c) 2011 by Journal of Lake Sciences

\title{
甘肃石羊河流域猪野泽湖泊沉积物粒度敏感组分与花粉组合关系"
}

\author{
李 育, 王乃昂, 李卓仑 \\ (兰州大学资源环境学院,干旱区水循环与水资源研究中心,兰州 730000)
}

\begin{abstract}
摘 要: 在石羊河终端湖猪野泽全新世探井剖面, 对连续不同间距 368 组和 74 组样品, 进行粒度测量与花粉分析. 结果表 明, 沉积物不同粒度敏感组分与典型花粉组合有很好的相关性. 花粉总浓度及麻黄 (Ephedra)、白刺 (Nitraria)、藜科( Chenopodiaceae)、香蒲属 (Typha)、云杉属 (Picea) 的花粉百分比与小于 $89.31 \mu \mathrm{m}$ 三个粒度范围的敏感组分存在正相关关系, 与大于 $89.31 \mu \mathrm{m}$ 两个粒度范围的组分存在负相关关系. 桦木 (Betula)、栋 ( Quercus)、寽麻属 (Urtica) 的花粉百分比与大于 $89.31 \mu \mathrm{m}$ 三种粒度敏感组分存在明显正相关关系. 沉积物花粉组合与粒度敏感组分之间相关关系, 主要受控于流域水分 条件及相应的湖泊水位, 同时也受到流域风沙活动的影响. 沉积物中与细颗粒组分正相关关系的花粉指标, 主要受到较 好的流域水动力条件和高湖面的影响; 而与粗颗粒正相关的花粉指标, 则与低湖面及风沙作用有关. 当流域水分较好,终 端湖水位较高的时期, 总花粉浓度及河流传播的花粉百分含量较高; 流域气候较干燥时期,总花粉浓度较低, 风媒花粉的 百分含量较高. 最后, 本文结合猪野泽湖泊沉积物粒度敏感组分与花粉组合的关系, 将猪野泽地区晚冰期以来的气候、环 境变化过程分为 6 个阶段,其中早、中全新世气候较湿润,晚冰期及晚全新世期间气候相对较干燥.
\end{abstract}

关键词: 猪野泽; 湖泊沉积物; 粒度敏感组分; 花粉组合; 石羊河流域

\section{Relationship between grain-size sensitive components and pollen assemblages in the lake sediments of Lake Zhuye, Shiyang River Basin, Gansu Province}

\section{Yu, WANG Nai'ang \& LI Zhuolun}

(College of Earth and Environmental Sciences, Center for Hydrologic Cycle and Water Resources in Arid Region, Lanzhou University, Lanzhou 730000 , P. R. China)

\begin{abstract}
We hand-excavated a profile named QTH02 in a terminal lake in Shiyang River, Lake Zhuye. The QTH02 was sampled at $2 \mathrm{~cm}$ intervals in which 368 samples were yielded for analysis of grain-size, and sampled at $10 \mathrm{~cm}$ intervals in which 74 samples were yielded for pollen analysis. Based on the correlation analysis, the results showed that the variables between sensitive components of the grain-size and pollen assemblages are related with each other. The total pollen concentration and percentages of Ephed$r a$, Nitraria, Chenopodiaceae, Typha and Picea are positively correlated with the grain-size sensitive components that the sizes are less than $89.31 \mu \mathrm{m}$, and negatively correlated with the grain-size sensitive components that the sizes are larger than $89.31 \mu \mathrm{m}$. The percentages of Betula, Quercu, and Urtica are positively correlated the grain-size sensitive components that the sizes are more than 89. $31 \mu \mathrm{m}$. The correlation between the pollen assemblages and grain-size sensitive components is mainly controlled by the moisture conditions of the basin and water level of the Lake Zhuye, which is also affected by wind transportation. The pollen proxies which are correlated with the fine components are mainly affected by the hydrodynamics of the drainage basin and high lake-level, and the pollen proxies which are correlated with the coarse components are mainly affected by low lake-level and eolian activities. While the drainage basin is relatively humid and the lake-level is relatively high, the total pollen concentration and percentages of river-transported pollen are relatively high. While the drainage basin is relatively arid, the total pollen concentration is relatively low, but the percentages of wind-transported pollen are relatively high. Then, based on the relationships between the grain-size sensitive components and pollen assemblages, we divided the climatic and environmental changes in Lake Zhuye since the Late Clacial into six stages. The climate is moist in the Early and Middle Holocene but dry in the Late Clacial and Late Holocene.
\end{abstract}

* 国家自然科学基金项目 (41001116) 和兰州大学中央高校基本科研业务专项资金 (lzujbky - 2010 - 99) 联合资助. 2010-05-24 收稿;2010-07-12 收修改稿. 李育,男,1981 年生,博士,讲师;E-mail:liyu@ lzu. edu. cn. 
Keywords: Lake Zhuye; lacustrine sediments; sensitive grain-size to environments; pollen assemblages; Shiyang River Basin

湖泊沉积物中粒度组分和花粉组合研究是古环境重建中两个重要的代用指标 ${ }^{[1-6]}$. 根据水动力学原理, 沉积物颗粒的大小主要揭示沉积物来源、湖泊及人湖水系的水动力过程 ${ }^{[7-8]}$; 通过不同的数学模型对粒度组 分进行分离, 探讨不同组分的环境意义, 及通过特殊粒度组分进行古环境重建都已经取得了长足的进 展 ${ }^{[-13]}$. 花粉组合则主要反映流域及临近区域的植被组成 ${ }^{[14-16]}$, 在对花粉的沉积过程研究中, 许多研究认为 河流是湖泊花粉的主要来源 ${ }^{[17-20]}$, 而在干旱区盐湖中, 有研究认为风媒对花粉传播的贡献很高 ${ }^{[21-22]}$. 这种花 粉传播机制方面的争论, 成为通过花粉重建古环境中对花粉环境意义解释的难题. 在 20 世纪, 曾有学者采 用花粉散布模型方式来解决花粉的来源及散布面积问题 ${ }^{[23-25]}$, 但该方法在流域地形变化较大、传播途径复 杂的区域不能得到很好的应用. 因此, 如何在这种流域地形变化较大、传播途径复杂的区域探讨花粉传播机 制就成为一个值得深入探讨的问题.

根据粒度分布曲线的特征可确定组分数和分布类型 ${ }^{[8]}$, 不同的分布类型代表着不同的沉积物传播的动 力来源 ${ }^{[7-8]}$. 因此, 将沉积物粒度指标与花粉组合结合研究, 在理论上可以为花粉传播过程提供沉积物动力 来源基础. 如果能对这两者之间关系进行探讨, 不仅对花粉传播机制研究方面有所贡献, 同时对古环境中代 用指标的解释也有很大帮助.

基于上述原因, 本文选择粒级-标准偏差模型分离粒度敏感组分的方法, 通过分析沉积物中粒度敏感组 分与花粉组合之间的相关性, 探讨粒度与花粉组合之间的关系, 借此探究这种新方法在解释花粉传播机制 方面的可行性.

本文的作者已经撰文探讨了不同阶段猪野泽沉积物花粉组成与粒度组合的关系 ${ }^{[26]}$, 然而分阶段讨论 中, 没有涉及花粉的传播及沉积过程, 花粉的传播及沉积过程是理解沉积物中花粉组合古环境意义的基础. 本文拟从粒度敏感组分人手, 研究其与花粉组合的关系, 从而分析花粉的传播及沉积过程. 本文首先计算了 猪野泽沉积物的粒度敏感组分, 采用相关分析的方法, 研究全剖面各种粒度敏感组分和花粉组合的相关性, 并基于此种相关性探索花粉的传播过程及其古环境指示意义.

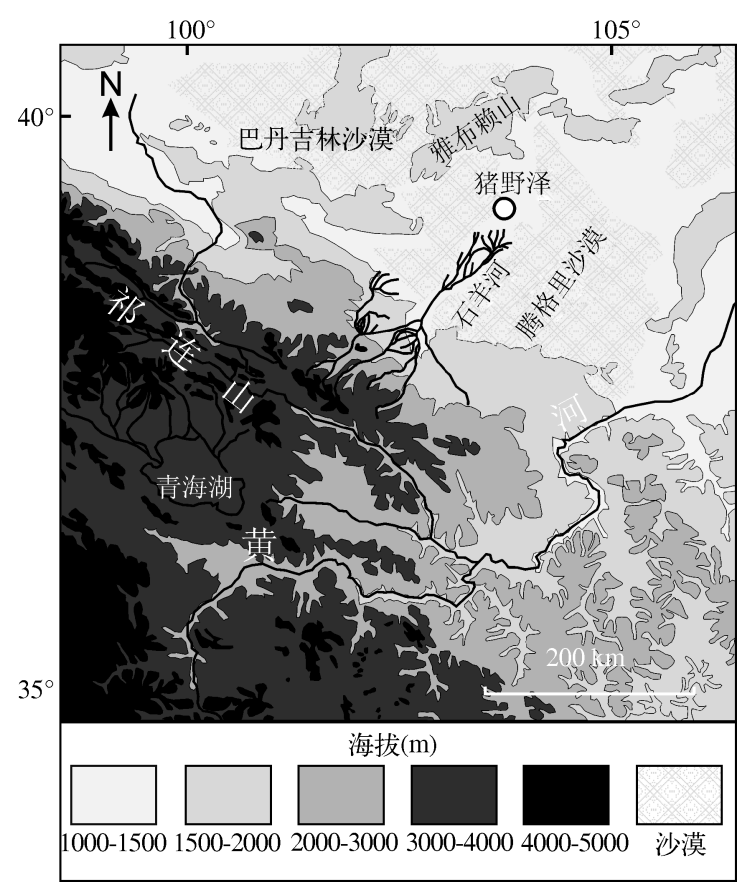

图 1 研究区示意图

Fig. 1 Map showing the research area

\section{1 研究区、研究材料及实验方法}

石羊河流域 $\left(37^{\circ} 02^{\prime}-39^{\circ} 17^{\prime} \mathrm{N}, 100^{\circ} 57^{\prime}-104^{\circ}\right.$ $57^{\prime} \mathrm{E}$ ) 位于甘肃省河西走廊东部, 祁连山北麓, 流 域全长 300 余公里, 总面积 $4.16 \times 10^{4} \mathrm{~km}^{2}$ (图 1). 按我国自然地理区划, 石羊河流域处于我国 西北内陆干旱区与东部季风区的交汇过渡地带, 该流域现代气候受到亚洲季风与西风带气流的共 同影响 ${ }^{[27-28]}$. 流域自南向北大致划分为三个气候 区, 南部祁连山高寒半干旱湿润区: 海拔 $2000-$ $5000 \mathrm{~m}$, 年降水量 $300-600 \mathrm{~mm}$, 年蒸发量 $700-$ $1200 \mathrm{~mm}$, 该区植被分为高山垫状植被带 [代表性 植物有垫状点地梅 (Androsace tapete)、垫状驼线 㢣(Ceratoides compacta) 等]、高山草甸带[代表性 植物有嵩草属 (Kobresia) 等]、高山灌丛带 [代表 性植物有杜鹃花属 (Rhododendron)、金露梅 (Potentilla fruticosa) 等]、森林带 [代表性植物有(云 杉(Picea)、圆柏 (Sabina)、杨属 (Populus)、桦属 (Betula) 等]、山前草甸草原 [ 短花针茅 (Stipa breviflora)、䓅菆草 (Achnatherum splendens) 等]; 中部 平原温良干旱区: 海拔 $1500-2000 \mathrm{~m}$, 年降水量 
$150-300 \mathrm{~mm}$, 年蒸发量 $1300-2000 \mathrm{~mm}$, 该区域为荒 漠草原带 [以禾本科 (Poaceae) 为主, 伴有旱生半灌 木、灌木 ] 北部温暖干旱区:海拔 $1300-1500 \mathrm{~m}$, 年 降水量小于 $150 \mathrm{~mm}$, 年蒸发量 $2000-2600 \mathrm{~mm}$, 该区 域植被为荒漠植被 $[$ 代表性植物有梭梭 (Haloxylon ammodendion)、白刺 ( Nitraria)、膜果麻黄 (Ephedra przewalskii $)$ 等 $]^{[29-30]}$. 朱艳等 ${ }^{[31]}$ 研究了石羊河流域 的空气、表土、河水和河床冲积物中的狍粉组合特 征,其结果显示该流域河流搬运狍粉的能力较风力 强,河水搬运的孢粉对中下游河床冲积物及河水孢 粉谱的贡献量非常大, 并得出在终端湖沉积物中以 云杉属 (Picea) 为代表的山地乔木花粉主要受河水 搬运的结论. 程波等 ${ }^{[32]}$ 通过对石羊河流域不同植被 带 76 个表土样的狍粉分析,研究了该流域各植被 带的表土狍粉组合及主要植物花粉与其植物比例 的关系. 结果表明,石羊河流域各科属狍粉与植物 之间的关系复杂, 同一科属狍粉在不同植被带中的 代表性也各有差异,所以某科属狍粉的代表性问题 需要在不同植被带中分别讨论. 根据石羊河流域现 代花粉学研究, 该区域沉积物花粉受到河水、风力 搬运的综合影响,传播途径复杂,所以在该流域展 开沉积地层中花粉组合与粒度敏感组分的研究, 并 探讨不同层位花粉传播机制及环境意义非常必要.

研究区猪野泽是石羊河下游终端湖,位于民勤 县中渠乡志云村北, 目前已经干涸. 剖面点地理坐 标为 $39^{\circ} 03^{\prime} \mathrm{N}, 103^{\circ} 40^{\prime} \mathrm{E}$, 海拔 $1309 \mathrm{~m}$ ( 图 1), 在剖面 点处相距 $10 \mathrm{~m}$ 开挖了两个平行探井剖面— QTH01 和 QTH02, 剖面深度分别为 $692 \mathrm{~cm}$ (QTH01) , 736cm( QTH02). 本文分析的粒度与花粉 样品均采集于 QTH02 剖面, 两个剖面均为自下至上 连续系统采样, 粒度样品以 $2 \mathrm{~cm}$ 间隔采集, 共采得 368 个样品; 花粉样品以 $10 \mathrm{~cm}$ 间隔连续采样, 共采

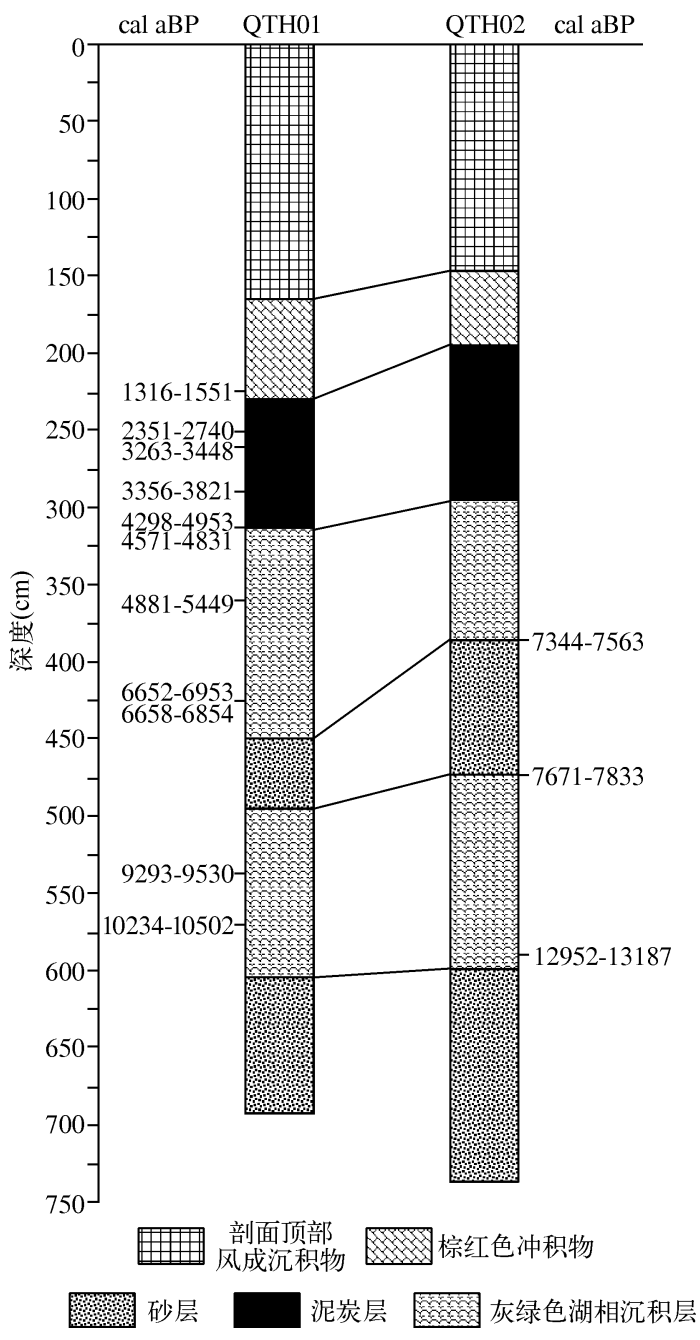

图 2 剖面示意图及年代结果

Fig. 2 The dates and lithology at QTH01 and QTHO2 sections 得 74 个样品. 根据 QTH01 和 QTH02 剖面的岩性、 粒度、C/N、总有机碳 $(T O C)$ 、有机碳同位素等指标的综合分析, 并结合粒度频率曲线的特征, 将 QTH01 和 QTH02 剖面的层位分为湖相、砂层、风积相、河流相等. 具体的沉积物环境代用指标分析过程及剖面的年代 测定参照 $\mathrm{Li}$ 等的方法 ${ }^{[14]}$ (图 2).

沉积物粒度测试在兰州大学西部环境教育部重点实验室的 Mastersizer2000 激光粒度分析仪上进行. 样 品测试前的处理过程如下: 细颗粒的湖相粉沙质粘土样品约 $0.3 \mathrm{~g}$, 较粗颗粒的浅湖相取约 $0.4-0.5 \mathrm{~g}$, 粗颗 粒的砂样品量相应增加; 首先加人 $10 \mathrm{ml} \mathrm{H}_{2} \mathrm{O}_{2}$, 去除沉积物中的有机质, 然后加人 $10 \mathrm{ml} \mathrm{HCl}$, 加热煮沸去除碳 酸盐物质; 用蒸馏水清洗样品两次, 每次间隔 $12 \mathrm{~h}$; 清洗后的样品以备激光粒度仪测试用. 正式在激光仪上测 试前, 加人 $10 \mathrm{ml}$ 分散剂 $\left(\mathrm{NaPO}_{3}\right)_{6}$, 将样品在超声波震荡仪上震荡 $10 \mathrm{~min}$, 使颗粒充分分散.

根据样品的岩性, 沙质土样品取样 $80 \mathrm{~g}$, 其余样品取样 $40 \mathrm{~g}$ 进行花粉分析. 花粉提取采用常规的氢氟酸 篮选法 (所用的尼龙篮布孔径为 $10 \mu \mathrm{m}$ ) 和重液浮选的方法 (含沙量较高的样品花粉浓度很低不适合于单纯 的篮选法, 需用重液浮选法配合 $)^{[33]}$. 样品处理前加人定量 (11670 粒) 石松狍子, 以统计计算花粉浓度. 花粉 
鉴定统计在 400 倍 Olympus 光学显微镜下进行, 样品鉴定统计花粉 500 粒以上, 在个别花粉浓度很小的层 位, 鉴定数量均超过 100 粒. 观察统计玻片 5 个以上, 如果样品花粉较少则观察统计更多的玻片, 直至达到要 求或样品用完.

\section{2 结果}

\section{1 粒度敏感组分计算及相关性分析}

粒级-标准偏差模型分离出的粒度敏感组分可以很好的指示沉积物输运过程和沉积环境变化,已较好 地应用于阿拉伯海、中国南海和冲绳海槽 ${ }^{[12,34-35]}$. 本文运用粒级-标准偏差模型分离出 5 个粒度敏感组分

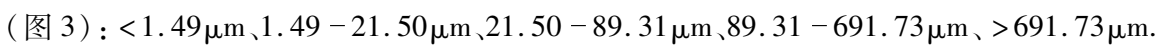

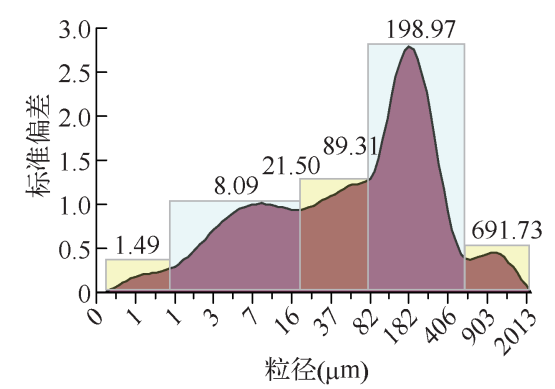

图 3 QTH02 剖面 368 组粒度百分比数据 计算所得的粒级-标准偏差曲线

Fig. 3 The grain size-standard deviation curve calculated from the percentage of grain size

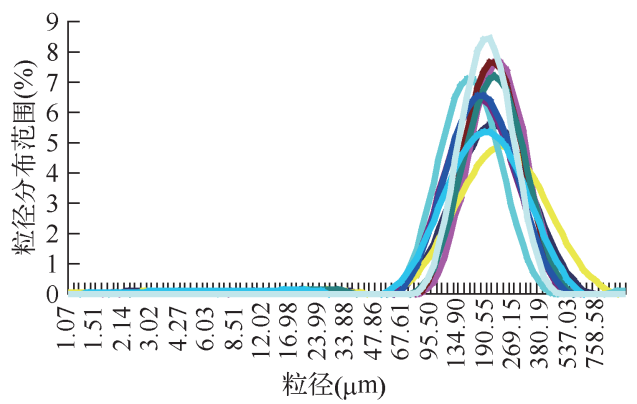

图 4 本区域地表风成砂表土样口粒度频率曲线 （表土样品编号 TZQ-1、CGBL-2、HST-1、MWM-1、 MWM-3、BCJ-1 、BCJ-2、WZMG、YHZSY 、ZZS-2)

Fig. 4 The grain size frequency curves of surface aeolian sand samples

\section{2 花粉分析结果及花粉指标与粒度敏感组分的相关性分析}

用于花粉分析的 QTH02 剖面样品共 74 个,共鉴定出 50 余科属. 本文选取该区域常见的, 并在整个剖面 占有优势的 11 种花粉类型, 分析不同花粉与不同粒度敏感组分之间的关系, 这些花粉类型包括松属 $(P i-$ $n u s) 、$ 桦木 (Betula)、云杉属 (Picea)、栋( Quercus)、白刺 (Nitraria)、蒿属 (Artemisia)、麻黄 (Ephedra)、香蒲属 (Typha)、藜科 (Chenopodiaceae)、尊麻属 (Urtica)、伞形科 (Umbelliferae), 同时也计算了总花粉浓度, 乔木花 粉浓度,灌木花粉浓度和草本花粉浓度四个花粉浓度指标.

由于用于花粉分析和粒度分析的样品采样间隔分别为 $10 \mathrm{~cm}$ 和 $2 \mathrm{~cm}$, 为了准确对粒度敏感组分和花粉 组合进行相关分析, 故对每个花粉样品对应的 5 个粒度样品测量结果进行平均, 将粒度分辨率调整到与花 粉样品一致的分辨率, 从而使粒度与花粉之间可以进行完全的对比.

通过计算得到不同花粉含量和各粒度敏感组分之间的相关系数 (表 1 ), 麻黄、白刺、穅科、香蒲属的花粉 百分比和花粉总浓度 (Total Concentration)、乔木花粉浓度 (Tree con. )、灌木花粉浓度 (Shrub con.) 、草本花 粉浓度 (Herb con.) 与 $<1.49 \mu \mathrm{m} 、 1.49-21.50 \mu \mathrm{m} 、 21.50-89.31 \mu \mathrm{m}$ 三个粒度范围的组分, 存在显著的正相 关关系, 与 $89.31-691.73 \mu \mathrm{m}$ 粒度组分存在显著负相关关系, 与 $>691.73 \mu \mathrm{m}$ 粒度组分存在负相关关系. 桦 木、栋、菖麻属的花粉百分比与 $89.31-691.73 \mu \mathrm{m}$ 粒度组分存在显著正相关关系, 与 $>691.73 \mu \mathrm{m}$ 粒度组分 存在正相关关系, 与 $<1.49 \mu \mathrm{m} 、 1.49-21.50 \mu \mathrm{m} 、 21.50-89.31 \mu \mathrm{m}$ 三种粒度组分存在显著负相关关系. 云杉 属花粉与 $<1.49 \mu \mathrm{m} 、 1.49-21.50 \mu \mathrm{m} 、 21.50-89.31 \mu \mathrm{m}$ 三个粒度范围的组分存在正相关关系与 $89.31-$ $691.73 \mu \mathrm{m} 、>691.73 \mu \mathrm{m}$ 两个粒度范围的组分存在负相关关系, 但都不显著. 蒿属与松属花粉与各个粒度敏 感组分相关性不显著, 伞形科花粉的百分比与 $21.50-89.31 \mu \mathrm{m}$ 粒度组分相关性显著, 与其他粒度组分相关 性不显著. 
表 1 粒度敏感组分与花粉组合相关系数

Tab. 1 The correlation coefficients between pollen assemblages and grain-size sensitive components

\begin{tabular}{cccccc}
\hline 花粉 & $<1.49 \mu \mathrm{m}$ & $1.49-21.50 \mu \mathrm{m}$ & $21.50-89.31 \mu \mathrm{m}$ & $89.31-691.73 \mu \mathrm{m}$ & $>691.73 \mu \mathrm{m}$ \\
\hline Picea & 0.114 & 0.118 & 0.165 & -0.164 & -0.073 \\
Ephedra & $0.297^{*}$ & $0.246^{*}$ & $0.229^{*}$ & $-0.289^{*}$ & -0.187 \\
Nitraria & $0.355^{*}$ & $0.364^{*}$ & $0.257^{*}$ & $-0.392^{*}$ & -0.119 \\
Artemisia & $0.045^{*}$ & 0.059 & -0.046 & -0.015 & -0.098 \\
Chenopodiaceae & $0.380^{*}$ & $0.393^{*}$ & 0.123 & $-0.359^{*}$ & 0.016 \\
Typha & $0.294^{*}$ & $0.331^{*}$ & 0.162 & $-0.324^{*}$ & $-0.036^{*}$ \\
花粉总浓度 & $0.218^{*}$ & $0.206^{*}$ & $0.207^{*}$ & $-0.254^{*}$ & -0.054 \\
乔木花粉浓度 & $0.340^{*}$ & $0.386^{*}$ & $0.481^{*}$ & $-0.403^{*}$ & 0.022 \\
灌木花粉浓度 & $0.187^{*}$ & $0.213^{*}$ & 0.161 & -0.094 & $-0.288^{*}$ \\
草本花粉浓度 & $0.255^{*}$ & $0.302^{*}$ & $0.409^{*}$ & $-0.322^{*}$ & -0.016 \\
Pinus & -0.046 & $-0.055^{*}$ & -0.101 & 0.083 & 0.101 \\
Betula & $-0.202^{*}$ & $-0.217^{*}$ & $-0.286^{*}$ & $0.288^{*}$ & $0.200^{*}$ \\
Quercus & $-0.313^{*}$ & $-0.330^{*}$ & $-0.448^{*}$ & $0.458^{*}$ & 0.118 \\
Urtica & $-0.569^{*}$ & $-0.566^{*}$ & $-0.600^{*}$ & $0.688^{*}$ & $0.461^{*}$ \\
Umbelliferae & -0.067 & -0.097 & $0.345^{*}$ & -0.089 & -0.087 \\
\hline
\end{tabular}

*表示通过 0.1 的显著性检验.

\section{3 讨论}

\section{1 花粉浓度指标与粒度敏感组分关系}

由粒度敏感组分与花粉组合相关性分析可知,花粉浓度指标花粉总浓度、乔木花粉浓度、灌木花粉浓 度、草本花粉浓度与 $<1.49 \mu \mathrm{m} 、 1.49-21.50 \mu \mathrm{m} 、 21.50-89.31 \mu \mathrm{m}$ 三个粒度敏感组分存在正相关关系,与大 于 $89.31 \mu \mathrm{m}$ 两个组分存在负相关关系. 而小于 $89.31 \mu \mathrm{m}$ 的三个敏感组分之间呈明显的正相关性,在干旱区 湖泊沉积物中小于 $89.31 \mu \mathrm{m}$ 三个粒度范围的组分, 属于细颗粒组分. 这部分含量在全新世千年一百年尺度上 增加, 表示流域水分条件较好, 湖泊水量增加 ${ }^{[36-41]}, \mathrm{Li}$ 等对猪野泽环境重建结果也证明了这种粒度变化与湖 泊水量之间存在如上所述的关系 ${ }^{[14]}$. 因此, 当细粒组分增加, 流域水分条件较好, 植被覆盖度高, 花粉总浓度 等增加. 当湖泊粗颗粒增加、细颗粒减少, 指示了湖泊水位下降、流域水分较差, 植被覆盖度降低,花粉总浓 度等降低. 对比该区域典型的表土风成砂样品 (图 4), 湖泊沉积物粗颗粒的组分与风成砂的粒径分布范围相 似, 揭示了沉积物中粗颗粒组分与风成砂也有一定的关系, 当流域水分降低, 导致植被覆盖度低及风沙活动 强烈,其花粉总浓度等也相对降低.

\section{2 不同花粉百分比指标与粒度敏感组分关系及古环境重建}

麻黄、白刺、葱科、香蒲属、云杉的花粉百分比与小于 $89.31 \mu \mathrm{m}$ 三个粒度范围的组分存在正相关关系, 与 大于 $89.31 \mu \mathrm{m}$ 两个粒度范围的组分存在负相关关系. 麻黄、白刺、藜科三种植物是干旱区广泛分布的植物, 它们的含量和细颗粒组分正相关可以解释为: 细颗粒组分含量增多, 流域水分条件较好, 使干早区的植物密 度增加, 致使其在花粉百分比含量中增加. 香蒲属属于水生植物, 湖泊水量的大小自然会导致植物密度增加 或减小,使香蒲属百分含量与细颗粒组分呈现正相关关系. 流域上游祈连山东段植被以乔木云杉属、圆柏属 (Sabina)、松属为主, 混杂的山杨 (Populus) 及桦树等均为次生林, 次生植物分布较少, 密度不大 ${ }^{[42]}$. 云杉属 为上游山地的主要乔木, 在石羊河流域主要受流水传播 ${ }^{[31]}$, 其百分含量与细颗粒组分的正相关, 也可以解释 为上游水分条件较好,所携带的云杉属花粉较多,在终端湖沉积物中表现为花粉百分比上升. 关于这些花粉 与粗颗粒组分的负相关, 原理与花粉浓度相似, 细颗粒增加或减少与流域水分条件和植被密度有关.

华木、栋、榉麻属的花粉百分比与大于 $89.31 \mu \mathrm{m}$ 的粒度组分存在明显正相关关系. 这三种植物都不是本 区域广泛分布的植物, 前两种乔木在上游山地分布也不广泛. 这三种花粉与粗颗粒物质正相关, 因为粗颗粒 组分物质含量增多时期,水分条件较差, 植被密度较小, 流域内部原来在水分条件较好的时候占有较大百分 
比的花粉, 大幅度减小, 同时代表整个区域背景值的外来花粉组分相应增多, 从而导致桦木、栋、菖麻属的花 粉百分比与粗颗粒组分的正相关及与细颗粒组分的负相关.

蒿属与松属花粉与各个粒度敏感组分相关性不显著. 这两种植物在西北地区广泛分布, 传播途径较为 多样 ${ }^{[43]}$, 所以呈现出与粒度敏感组分的相关性不明显. 伞形科 (Umbelliferae) 花粉的百分比与 $21.50-$ $89.31 \mu \mathrm{m}$ 粒度组分相关性明显, 与其他组分相关性不明显, 由于伞形科花粉主要分布在较湿润的地貌部位, 如河漫滩、湖滨等, 而 $21.50-89.31 \mu \mathrm{m}$ 粒度组分是干旱区河流悬移组分的主要贡献部分 ${ }^{[44]}$. 伞形科花粉与 该组分的正相关, 解释为河流水量较大时期, 散落在河漫滩上的伞形科花粉会更多地随着悬移组分搬运到 终端湖沉积.

根据猪野泽湖泊沉积物粒度敏感组分与花粉组合关系可进一步重建该区域晚冰期以来气候及环境变 化过程, 可以将该区域环境变化过程分为 $A 、 B 、 C 、 D 、 E 、 F$ 六个阶段:

阶段 $\mathrm{A}(599-736 \mathrm{~cm}$, 约 $13 \mathrm{cal} \mathrm{kaBP}$ 之前) : 该段砂的百分比含量较高, 桦木 (Betula)、栋 ( Quercus)、菖麻 属 (Urtica) 的花粉百分含量较高, 总花粉浓度低, 说明该段湖泊水位较低、气候较干燥. 虽然桦木、栋、菖麻属 花粉百分含量较高, 但花粉产量少, 主要受风力传播, 代表大气这些花粉的背景值.

阶段 B $(473-599 \mathrm{~cm}$, 约 13 至约 7.7 cal kaBP), 该段沉积物细粒组分增加,云杉 (Picea) 花粉百分含量较 高,代表了上游地区降水和湿度增加. 该阶段湖泊面积扩大, 流域气候相对较湿润.

阶段 $\mathrm{C}(385-473 \mathrm{~cm}$, 约 7.7 至约 $7.4 \mathrm{cal} \mathrm{kaBP})$, 该段砂的百分比含量较高, 乔木花粉的含量大幅度减 小. 该阶段湖泊面积缩小,流域气候相对干旱.

阶段 D(199-385cm, 约 7.4 至约 $1.5 \mathrm{cal} \mathrm{kaBP})$, 该段沉积物细粒组分增加, 总花粉浓度达到了全新世的 最高值. 该段湖泊水位较高, 流域植被覆盖度高, 气候较湿润.

阶段 $\mathrm{E}(147-199 \mathrm{~cm}, 1.5-1.1 \mathrm{cal} \mathrm{kaBP})$, 该段细颗粒组分较多, 但总花粉浓度相对于上一阶段较低, 该 阶段沉积物为红褐色的粉砂质粘土并伴有许多褐色锈斑, 说明该阶段湖泊退缩, 该种沉积物可能为冲积相 沉积物.

阶段 $\mathrm{F}(1-147 \mathrm{~cm}$, 约 1.1 至 $0 \mathrm{cal} \mathrm{kaBP})$, 该段沉积物为灰黄色或褐黄色砂粘土或粉砂, 并不是典型的湖 相沉积, 总花粉浓度较低, 说明该段湖泊面积继续缩小, 总植被覆盖度减小, 气候干旱.

致谢: 感谢程弘毅博士、赵强博士、隆浩博士参加野外工作, 感谢两位审稿人给本文提出宝贵的修改意见, 感 谢编辑辛勤的工作.

\section{4 参考文献}

[ 1 ] Peng Y, Xiao J, Nakamura T et al. Holocene East Asian monsoonal precipitation pattern revealed by grain-size distribution of core sediments of Daihai Lake in Inner Mongolia of north-central China. Earth and Planetary Science Letters, 2005 , 233 : $467-479$.

[2] 沈吉, 汪 勇, 羊向东等. 湖泊沉积记录的区域风沙特征及湖泊演化历史: 以陕西红碱淖湖泊为例. 科学通报, $2006, \mathbf{5 1}(1): 87-92$.

[ 3 ] 孙千里,周 杰, 肖举乐. 岱海沉积物粒度特征及其古环境意义. 海洋地质与第四纪地质,2001,21(1):93-95.

[ 4 ] Xiao J, Xu Q, Nakamur T et al. Holocene vegetation variation in the Daihai Lake region of north-central China: a direct indication of the Asian monsoon climatic history. Quaternary Science Review, 2004, 23 : 1669-1679.

[ 5 ] Herzschuh U, Kürschner H, Mischke S. Temperature variability and vertical vegetation belt shifts during the last $\sim 50,000 \mathrm{yr}$ in the Qilian Mountains (NE margin of the Tibetan Plateau, China). Quaternary Research, 2006, 66 : 133146.

[6] 刘兴起, 沈 吉, 王苏民等. 青海湖 16ka 以来的花粉记录及其古气候古环境演化. 科学通报, 2002,47(17): 1351-1355.

[ 7 ] Sun D, Bloemendal J, Rea DK et al. Grain size distribution function of polymodal sediments in hydraulic and Aeolian environments and numerical partitioning of the sedimentary components. Sedimentary Geology, 2002, 152 : 263-277.

[8] 孙东怀, 安芷生, 苏瑞侠等. 古环境中沉积物粒度组分分离的数学方法及其应用. 自然科学进展, 2001, 11(3): 269-276. 
[ 9 ] Prins MA, Postma G, Cleveringaa J et al. Controls on terrigenous sediment supply to the Arabian Sea during the late Quaternary: the Indus Fan. Marine Geology, 2000, 169: 327-349.

[10] Prins MA, Weltje GJ. End-member modeling of siliciclastic grain size distributions: The late Quaternary record of eolian and fluvial sediment supply to the Arabian Sea and its paleoclimatic significance. In: Harbaugh J, Watney L, Rankey G et al eds. Numerical Experiments in Stratigraphy: Recent Advances in Stratigraphic and Sedimentologic Computer Simulations, SEPM (Society for Sedimentary Geology) Special Publication, 1999, 62: 91-111.

[11] Stuut JBW, Prins MA, Schneider R et al. A $3002 \mathrm{kyr}$ record of aridity and wind strength in southwestern Africa: Inferences from grain size distributions of sediments on Walvis Ridge, SE Atlantic. Marine Geology, 2002, 180: 221-233.

[12］孙有斌,高 抒,李 军. 边缘海陆源物质中环境敏感粒度组分的初步分析. 科学通报,2003,48(1):83-87.

[13] Boulay S, Colin C, Trentesaux A et al. Mineralogy and sedimentology of Pleistocene sediments on the South China Sea (ODP Site 1144). Proceedings of the Ocean Drilling Program, Scientific Results, 2002: 184.

[14] Li Y, Wang N, Cheng H et al. Holocene environmental change in the marginal area of the Asian monsoon: a record from Lake Zhuye, NW China. Boreas, 2009, 38: 349-361.

[15] 萧家仪,吕海波,周卫健等. 末次盛冰期以来江西大湖花粉植被与环境演变. 中国科学 (D 辑) : 地球科学, 2007,37 (6) :789-797.

[16] 马春梅, 朱 诚, 郑朝贵等. 中国东部山地泥炭高分辨率腐殖化度记录的晚冰期以来气候变化. 中国科学 (D 辑): 地球科学, $2008, \mathbf{3 8}(9): 1078-1091$.

[17] Vincens A, Bonnefille R. Modern pollen sedimentation in Africa lakes. Brisbane: 7th International Palynology Congress, 1988: 173 .

[18] Bony AP. Seasonal and annual variation over 5 years in contemporary airborne pollen teapped at a Cumbrian Lake. Journal of Ecology, 1980, 68: 421-441.

[19] DeBusk GH. The distribution of pollen in the surface sediments of lake Malawi, Africa, and the transport of pollen in large lakes. Review of Palaeobotany and Palynology, 1997, 97 : 123-153.

[20] 朱 艳, 陈发虎, Madsen BD. 石羊河流域早全新世湖泊狍粉记录及其环境意义. 科学通报, 2001,46 (19): 1596-1602.

[21] Luly JG. Modern pollen dynamics and surficial sedimentary processes at Lake Tyrrell, semi-arid northwestern Victoria, Australia. Review of Palaeobotany and Palynology, 1997, 97: 301-318.

[22] 尚 雪,李小强,安芷生等. 青海湖流域表土花粉分析. 中国科学 (D 辑) : 地球科学,2009,39(9) :1288-1296.

[23] Prentice IC. Pollen representation, source area and basin size; toward a unified theory of pollen analysis. Quaternary Research, 1985, 23: 76-86.

[24] Sugita S. A model of pollen source area for an entire lake surface. Quaternary Research, 1993, 39: 239-244.

[25] Sugita S. Pollen representation of vegetation in Quaternary sediments: theory and method in patchy vegetation. Journal of Ecology, 1994, 82: 881-897.

[26] Li Y, Wang N, Morrill C et al. Environmental change implied by the relationship between pollen assemblages and grainsize in N. W. Chinese lake sediments since the Late Glacial. Review of Palaeobotany and Palynology, 2009, 154: 54-64.

[27] 中国科学院《中国自然地理》编辑委员会. 中国自然地理气候. 北京:科学出版社, 1984:1-30.

[28 ] Chen F, Yu Z, Yang M et al. Holocene moisture evolution in arid central Asia and its out-of-phase relationship with Asian monsoon history. Quaternary Science Reviews, 2008, 27 : 351-364.

[29］陈隆亨,曲耀光. 河西地区水土资源及其开发利用. 北京:科学出版社,1992:6-46.

[30］黄大壆. 甘肃植被.兰州:甘肃科学技术出版社,1997:163-176.

[31] 朱 艳,程 波,陈发虎等.石羊河流域现代狍粉传播研究.科学通报,2004,49(1):15-21.

[32] 程 波,朱 艳,陈发虎等. 石羊河流域表土狍粉与植被的关系. 冰川冻土,2004, 26(1):81-88.

[33 ] Faegri K, Iverson J, Appendix A. In: Faegri K, Kaland PE, Krzywinski K eds. Textbook of pollen analysis. New York: Blackwell, 1989: 69-89.

[34] Wang L, Sarnthein M, Erlenkeuzer H et al. East Asian monsoon climate during the late Pleistocene: High resolution sediment records from the South China Sea. Marine Geology, 1999, 156 : 245-284.

[35] Rea DK, Hovan SA. Grain size distribution and depositional processes of the mineal component of abyssal sediments: Lessons from the North Pacific. Paleoceanography, 1995, 12 : 251-258. 
[36] 陈敬安, 万国江, 张 峰等. 不同时间尺度下的湖泊沉积物环境记录一以沉积物粒度为例. 中国科学 ( D 辑): 地 球科学, $2003,33(6): 563-568$.

[37] 薛积涁,钟 巍. 新疆巴里坤湖全新世环境记录及区域对比研究. 第四纪研究,2008,28(4):610-620.

[38 ] Bioerck S, Olsson S, Ellis-Evans C et al. Late Holocene palaeoclimatic records from lake sediments on James Ross Island, Antarctica. Palaeogeography, Palaeoclimatology, Palaeoecology, 1996, 121 : 195-220.

[39] Dearing JA. Sedimentary indicators of lake-level changes in the humid temperate zone: a critical review. Journal of Paleolimnology, 1997, 18(1) : 1-14.

[40] Menking KM. Climatic signals in clay mineralogy and grain-size variations in Owens Lake core OL-92, eastern California. Geological Society of America Special Paper, 1997, 317: 25-36.

[41] Digerfeldt G, Olsson S, Sandgren P. Reconstruction of lake-level changes in lake Xinias, central Greece, during the last 40000 years. Palaeogeography, Palaeoclimatology, Palaeoecology, 2000, 158 : 65-82.

[42] 吴征镒. 中国植被. 北京:科学出版社,1980:749-1037.

[43] 许清海,李月丛, 阳小兰等. 中国北方几种主要花粉类型与植被定量关系. 中国科学 (D 辑) : 地球科学, 2007,37 (2) : 192-205.

[44] Middleton GV. Hydraulic interpretation of sand size distributions. Journal of Geology, 1976, 84: 405-426. 